\title{
Sporda Çeviklik Performansı
}

\author{
Serhat ÖZBAY*1, Süleyman ULUPINAR ${ }^{2}$, Abdullah Bora ÖZKARA ${ }^{3}$ \\ ${ }^{1}$ Erzurum Teknik Üniversitesi, Spor Bilimleri Fakültesi, https://orcid.org/0000-0001-6424-8871

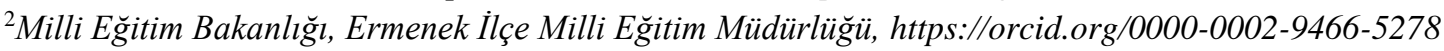 \\ ${ }^{3}$ Erzurum Teknik Üniversitesi, Spor Bilimleri Fakültesi, https://orcid.org/0000-0003-1688-3410
}

ÖZ

Derleme

Çeviklik sportif performansı etkileyen en önemli belirleyicilerden birisidir. Çeviklik, uyarana karşı tepki olarak verilen, tüm vücudun katılımını gerektiren, hızlı hareket edebilme, dengeyi koruma ve yön değiştirme gibi becerileri uyumlu bir şekilde gerçekleştirebilme yeteneği olarak tanımlanabilir. Çeviklik, diğer sportif becerilere göre daha karmaşık bir yapıya sahiptir. Bu kavramın içeriği, geliştirilmesi, ölçülmesi ve değerlendirilmesi konusunda birçok farklı görüş ortaya koyulmuştur. Çeviklik, eskiden yön değiştirme ve sürat gibi becerileri içeren, önceden planlanmış etkinlikler şeklinde değerlendirilirken, güncel çalışmalarda algılama ve karar verme gibi bilişsel faktörlerin çeviklik kavramının temelindeki unsurları oluşturdukları vurgulanmaktadır. Çeviklik performansı ile ilgili tanımlamalar ve değerlendirmeler spora özgü farklılıklar içerebilmektedir. Ayrıca çeviklik becerisini ölçmek için birçok farklı çeviklik testi geliştirilmiştir, ancak bu testlerin geçerliği, süresi, mesafesi ve tasarımı hakkında kabul görmemiş bazı hususlar vardır. Bunun yanında çeviklik performansının spor başarısındaki önemi herkes tarafindan kabul görse de, geliştirilmesi konusunda yeterli sayıda bilgi mevcut değildir. $\mathrm{Bu}$ sebeple bu çalışmanın amacı çeviklik kavramını tüm yönleriyle ele almak ve güncel çalışmalar ışı̆̆ında konuyla ilgili değişen yaklaşımları incelemektir. Sonuç olarak, çeviklik performansının geliştirilmesine yönelik alternatif antrenman yöntemi arayışları devam ederken, ölçme ve değerlendirme için de bütün bileşenlerin dahil edildiği yeni test yöntemleri geliştirmek için çalışmalar sürmektedir.
Anahtar kelimeler:

Çeviklik,

Yön değiștirme,

Çeviklik testleri

\section{Agility Performance in Sports}

\begin{abstract}
Agility is one of the most important determinants of sporting performance. Agility is the response given to the stimulus, requiring the participation of the whole body and the ability to react in a harmonious manner such as fast moving, balance protection and change of direction skills. Agility has a more complex structure than other sporting skills. There are many different views on the content, development, measurement and evaluation of this concept. It is emphasized that cognitive factors such as perception and decision making constitute the basis of the concept of agility in contemporary studies, while agility is formerly consisted of planned activities that includes skills such as change of direction and speed. Definitions and evaluations related to agility performance may include sportspecific differences. In addition, a number of different agility tests have been developed to measure agility, but there are some uncertain aspects of validity, duration, distance, and design of these tests. However, while everyone acknowledges the value of agility performance in sport performance, there is not enough information on its development. For this reason, the purpose of this study is to investigate all aspects of the concept of agility and to examine the changing approaches in contemporary studies. As a result, while the search for alternative training methods to improve agility performance continues, studying are being made to develop new test methods that include all components for measurement and evaluation.
\end{abstract}

Review Article

\footnotetext{
* Sorumlu yazar: Serhat ÖZBAY, serhat.ozbay@erzurum.edu.tr
}

Article Info

Received:24.09.2018

Accepted: 16.12 .2018 Online Published: 31.12.2018

(1)




\section{GíRiş}

Çeviklik kavramı içeriği, geliştirilmesi, ölçülmesi ve değerlendirilmesi konusunda birçok farklı görüş içeren ve hala araştırılmaya devam edilen sportif bir beceridir. Çeviklik ile ilgili çalışmalarda uzun yıllar boyunca, hareketleri hızlı gerçekleştirme, ani bir şekilde durma, yeniden başlama ve yön değiştirme gibi özellikleri içeren kalıplara yer verilmiştir (Chelladurai, 1976; Kirby, 1971; Zemkova, 2016). Günümüzde yapılan çalışmalar ise çeviklik için sürat, yön değiştirme ve kuvvet gibi fiziksel özelliklerin yanı sıra görsel tarama, sezgi, algılama ve karar verme gibi bilişsel faktörlerin de oldukça önemli olduğunu ortaya koymaktadır (Armstrong \& Greig 2018; Zemkova, 2016). Örneğin birçok spor topa, rakip oyuncuya ya da kendi takım arkadaşının hareketine tepki vermeyi gerektirir. Atletik performansın bu önemli bileşeni çeviklik olarak kabul edilmektedir ve başarı sağlamak için oldukça önemli olduğu belirtilmektedir (Greig \& Naylor, 2017; Young \& Farrow, 2006).

Çeviklik terimi spora özgü geniş bir yelpazede değerlendirilir ve farklı spor dalları için, farklı anlamlar taşımaktadır. Yani spor dalının gerektirdiği spesifik özellikler kapsamında istenilen hareket kalıplarına uygun çeviklik terimi kullanılabilmektedir (Greig \& Naylor, 2017; Sporis ve ark., 2010). Bu da çevikliğin tam olarak hangi bileşenlerden oluştuğu ve nasıl antrenman yöntemleri uygulanması gerektiği konusunda bazı görüş farklılıklarına yol açmaktadır (Sheppard \& Young, 2006; Turner, 2011; Young \& Farrow, 2006).

Çeviklik özellikle takım sporlarında performansın önemli bir belirleyicisi olarak kabul edilmektedir (Drake ve ark., 2017). Düz bir eksende koşu kilit bir atletik faktör olmasına rağmen, özellikle takım sporları başta olmak üzere birçok farklı branşta bir uyarana tepki olarak yön değiştirme, durma ve ivmelenmenin çoğunluğu oluşturduğu vurgulanmaktadır (Bradshaw, Young, Russell \& Burge, 2011; Mann ve ark., 2016). Örneğin, birçok sporda rakip oyuncudan başarıyla kurtulabilmek, aldatmak ya da yakalamak için top veya rakibe tepki vermek, daha çevik sporcuların avantaj sağladığı durumlar olarak belirtilmektedir (Paul, Gabbett \& Nassis, 2016).

\section{Çevikliğin Tanımlanması}

Çeviklik; denge, hız, kuvvet ve sinir-kas koordinasyonu işbirliğiyle iki nokta arasında vücudu hareket ettirme ve yön değiştirme becerilerini mümkün olduğunca kolay, hızlı, akıcı ve kontrollü bir şekilde yapabilmek olarak tanımlanmaktadır (Turner, 2011). Başka bir deyişle çevikliğin bir uyarana yanıt olarak tüm vücudun hız ve yön değiştirmeler olarak verdiği tepkiler olduğu belirtilmektedir (Sheppard \& Young, 2006).

Çeviklik, içeriğindeki faktörler konusunda farklı görüşlerin bulunması ve zaman içinde bu beceriye ilişkin bakış açılarının değişmesi sebebiyle araştırmacılar tarafından farklı şekillerde sınıflandırılmıştır. Özellikle yeni yaklaşımlarda bilişsel faktörlerin bu kavramda kilit bir rolünün olduğu ve eski çalışmalarda ise bunun göz ardı edildiği savunulmaktadır (Armstrong \& Greig, 2018; Greig \& Naylor, 2017; Zemkova, 2016). Örneğin, bir beyzbol oyununda topa vuran oyuncu üstleri dolaşmak için hızlı yön değiştirmeler içeren bir koşu yapar. Bu geleneksel bakış açısıyla çeviklik olarak tanımlansa da, aslında bu kavramı tam karşılamayan 
bir durum olarak değerlendirilmektedir (Young \& Farrow, 2006). Çünkü yön değiştirme içeren hareket kalıbı önceden planlanmıştır. Ama futbol ya da basketbol gibi birçok branşta rakibin ya da topun hareketi gibi bir uyarana yanıt olarak yön değiştirmeler yapıldı̆̆ belirtilmektedir (Paul, Gabbett \& Nassis, 2016; Young \& Farrow, 2006). Araştırmacılar, bu performansı değerlendirmek için kullanılan yöntemlerin, daha çok sürat ve yön değiştirme performansını ölçtüğü, bu sebeple bilişsel faktörler başta olmak üzere bu kavramı karşılayan tüm faktörleri ölçmede yetersiz kaldığını düşünmektedirler (Simonek, Horička \& Hianik, 2016; Zemkova, 2016; Zouhal ve ark., 2018).

Çeviklik ile ilgili çalışmalarda sprint, yön değiştirme, çabukluk, ivmelenme ve durma gibi bazı kavramlar çeviklik yerine kullanılmıştır. Ancak bu kavramlar, çevikliği oluşturan bileşenler ile ortak özelliklere sahip olsa da, tek başına çeviklik hakkında fikir vermesi beklenemez. Ayrıca çeviklikte bilişsel faktörlerin de duruma özgü gereksinimleri vardır. Yani sadece uyarana tepki vermek tek başına yeterli değildir. Bunun yanında uyaran hakkında bazı belirsizliklerin olması ve tepki, çeşitli alternatifler içerisinden en doğrusuna karar verme şeklinde gerçekleştirilmelidir. Aşağıda bir hareketin çeviklik tanımını karşılaması için bazı kriterler ortaya koyulmuştur.

Tablo 1. Çeviklik Becerisinin Kriterleri (Sheppard ve Young, 2006)

\begin{tabular}{|c|c|}
\hline Çeviklik & Diğer Beceriler \\
\hline $\begin{array}{l}\text { *Bir hareketi başlatma, yön değiştirme, hızlı } \\
\text { ivmelenme ya da ani yavaşlama hareketlerini } \\
\text { içermelidir. } \\
\text { *Tüm vëcudun katılımı oreklidir }\end{array}$ & $\begin{array}{l}\text { *Gülle atma gibi tamamen önceden planlanmış } \\
\text { becerileri, bir tür çeviklik olarak kabul etmek } \\
\text { yerine, kendi beceri fonksiyonlarına göre } \\
\text { sinıflandırmak gerekir. }\end{array}$ \\
\hline $\begin{array}{l}\text { *Uzaysal veya zamansal belirsizlik içermelidir. } \\
\text { *Sadece açı (opsiyonel) beceriler içermelidir. }\end{array}$ & $\begin{array}{l}\text { *Farklı yönlere yapılan koşular, çeviklik veya } \\
\text { çabukluk yerine, yön değiştirme hızı olarak kabul } \\
\text { edilmelidir. }\end{array}$ \\
\hline $\begin{array}{l}\text { *Fiziksel ve bilişsel katılım içermelidir. } \\
\text { Örneğin, bir uyaranın tanınması, reaksiyon } \\
\text { veya fiziksel bir yanıtın oluşmasını gerektirir. }\end{array}$ & $\begin{array}{l}\text { *Bir uyarana tepki gerektiren önceden } \\
\text { planlanmış ve tercih gerektirmeyen beceriler } \\
\text { (Örneğin sprint startında tabanca sesine yanıt } \\
\text { vermek) çeviklik değildir. }\end{array}$ \\
\hline
\end{tabular}

Yukarıda sözü edilen gülle atma gibi önceden planlanmış bir becerinin ya da yön değiştirme ve sprint koşularını içeren becerilerin çeviklik olarak değerlendirilmemesi gerektiğini vurgulamaktadır. Bir hareketin çeviklik olarak değerlendirilebilmesi için zamansal ya da uzaysal belirsizlikler içermesi ve bir uyarana yanıt olarak bilişsel faktörlerin de bu performansa dahil edilmesi gerekmektedir (Sheppard ve Young, 2006).

Sprint, kuvvet, yön değiştirme ve denge gibi becerilerin çevikliği etkilediği, fakat çeviklik performansını değerlendirmede hiç birinin tek başına yeterli olmayacağı düşünülmektedir (Armstrong \& Greig, 2018; Zemkova, 2016). Yani bir sporcu çok süratli ve çok iyi bir yön değiştirme kabiliyetine sahip olabilir ancak, algılama da ya da karar vermede yeterli değilse çevik olarak nitelendirilmemelidir. 


\section{Çevikliğin Sınıflandırılması}

Çevikliğin sınıflandırılmasında izlenecek yolların fazla olması, farklı sporlara ve farklı araştırmacılara göre değişik şekillerde yorumlanmasına sebep olmuştur. Chelladurai (1976), çeviklik hakkındaki ilk toparlayıcı bilgileri sunmuş ve çeviklik performansının sınıflandırılmasına ilişkin ilk çalışmalardan birini ortaya koymuştur. Bu çalışma daha sonra Sheppard ve Young (2006) tarafından uyarlanmış ve aşağıda sunulmuştur.

Tablo 2. Çevikliğin Sınıflandırılması (Chelladurai (1976), tarafından yapılan çalışma, Sheppard ve Young (2006), tarafından uyarlanmıştır.)

\begin{tabular}{|c|c|c|}
\hline $\begin{array}{l}\text { Çeviklik } \\
\text { Sınıfı }\end{array}$ & Tanım & Sportif Beceri Örneği \\
\hline Basit & $\begin{array}{l}\text { Mekansal ya da zamansal } \\
\text { belirsizlik yok }\end{array}$ & $\begin{array}{l}\text { Bir jimnastikçinin yer serisi: sporcunun kendi } \\
\text { isteğiyle başlayan ve önceden planlanmış etkinlikleri } \\
\text { içerir. Uyarıcı sporcunun kendi hareketi ve becerisini } \\
\text { sergilediği alandır. }\end{array}$ \\
\hline Zamansal & $\begin{array}{l}\text { Zaman belirsizdir ancak hareket } \\
\text { önceden planlanmıştır } \\
\text { (Mekan bellidir) }\end{array}$ & $\begin{array}{l}\text { Atletizm sprint startı: Bir uyarana yanıt olarak } \\
\text { başlayan, önceden planlanmış etkinlik içerir. } \\
\text { Tabancanın ne zaman ateşleneceğine dair bir kesinlik } \\
\text { yoktur. }\end{array}$ \\
\hline Uzaysal & $\begin{array}{l}\text { Mekan belirsizdir } \quad \text { ancak } \\
\text { hareketin zamanı önceden } \\
\text { planlanmıştır (Zaman bellidir) }\end{array}$ & $\begin{array}{l}\text { Voleybol veya teniste servis karşılama: Hakem } \\
\text { servisin atılması için dar bir zaman aralığı belirler ve } \\
\text { işaret verir. Servisi karşılayan oyuncunun ise servisin } \\
\text { nereye atılacağı konusunda kesin bir bilgisi yoktur. }\end{array}$ \\
\hline Evrensel & $\begin{array}{l}\text { Hem zaman hem de mekan } \\
\text { belirsizdir }\end{array}$ & $\begin{array}{l}\text { Buz hokeyi ya da futbol: Savunma veya hücum } \\
\text { sirasinda, sporcular rakip oyuncunun ne zaman ve } \\
\text { nereye hareket edecekleri konusunda kesin tahminleri } \\
\text { yoktur. }\end{array}$ \\
\hline
\end{tabular}

Çeviklik kavramına birçok farklı araştırmacı tarafından farklı anlamlar yüklenmiştir. Bu da çeviklik konusunda karmaşıklığa yol açan birçok farklı görüşe sebep olmuştur. Bu görüşleri bir çatı altında toplamak ve çeviklik performansının alt bileşenlerini temsil etmek amacıyla, Young ve ark., (2002) tarafindan bir model oluşturulmuştur. Bu model daha sonra Young ve Sheppard (2006) tarafından küçük değişikler yapılarak uyarlanmış ve aşağıda sunulmuştur. 


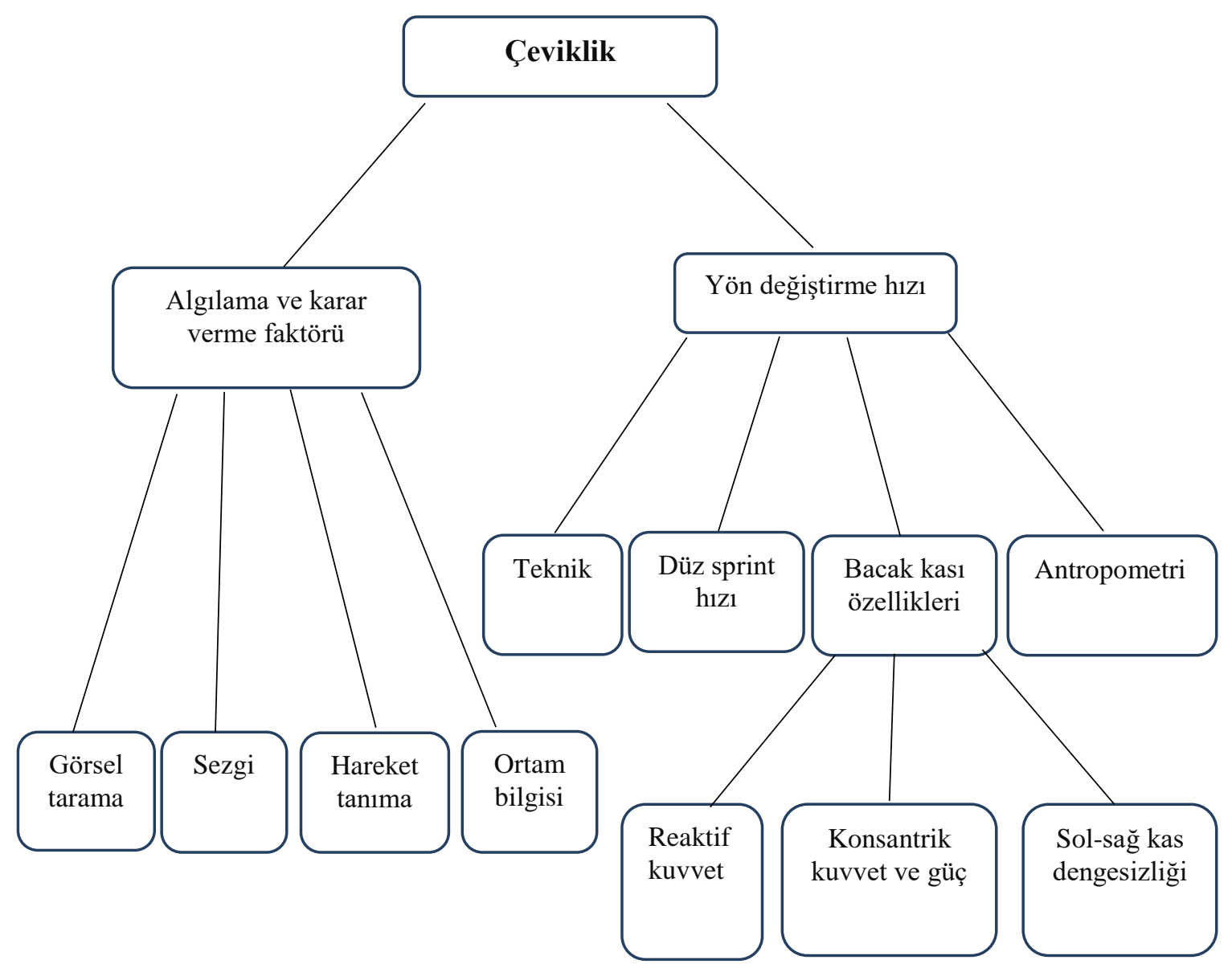

Şema 1. Çeviklik Performansının Belirleyici Modeli (Young ve ark. (2002), tarafindan yapılan çalışma, Sheppard ve Young (2006) tarafindan uyarlanmıștır)

Çeviklik performansı konusunda toparlayıcı bir bilgi sunan Sheppard ve Young (2006) kendinden sonraki birçok çalışma için referans oluşturan kapsamlı bir yapı ortaya koymuştur. $\mathrm{Bu}$ çalışmaya göre önceki çalışmalarda göz ardı edilen bilişsel özellikler çevikliğin mutlak unsuru olarak değerlendirilmelidir. Ayrıca yön değiştirme becerisi de teknik, sprint ve kuvvet gibi birçok etken tarafından şekillendirilmektedir. Dolayısıyla çevikliğin, fiziksel ve bilişsel birçok özelliğin sentezinden meydana geldiğini söylemek mümkündür. Bu özelliklerin her biri farklı oranda çeviklik performansına katkı sağlamaktadır. Geçmiş çalışmalarda çeviklik adı altında kullanılan hareket dizileri çevikliğin bazı alt bileşenleri hakkında bir veri sağlasa da daha kapsamlı bir ölçme ve değerlendirme yöntemine ihtiyaç vardır.

Benzer bir sınıflandırma Turner (2011) tarafından yapılmıştır. Bu çalışmada çeviklik performansı detaylı olarak sınıflandırılmış ve geliştirilmesi hususunda bütün bileşenleri dahil edecek şekilde antrenmanların tasarlanması gerektiği savunulmuştur. 


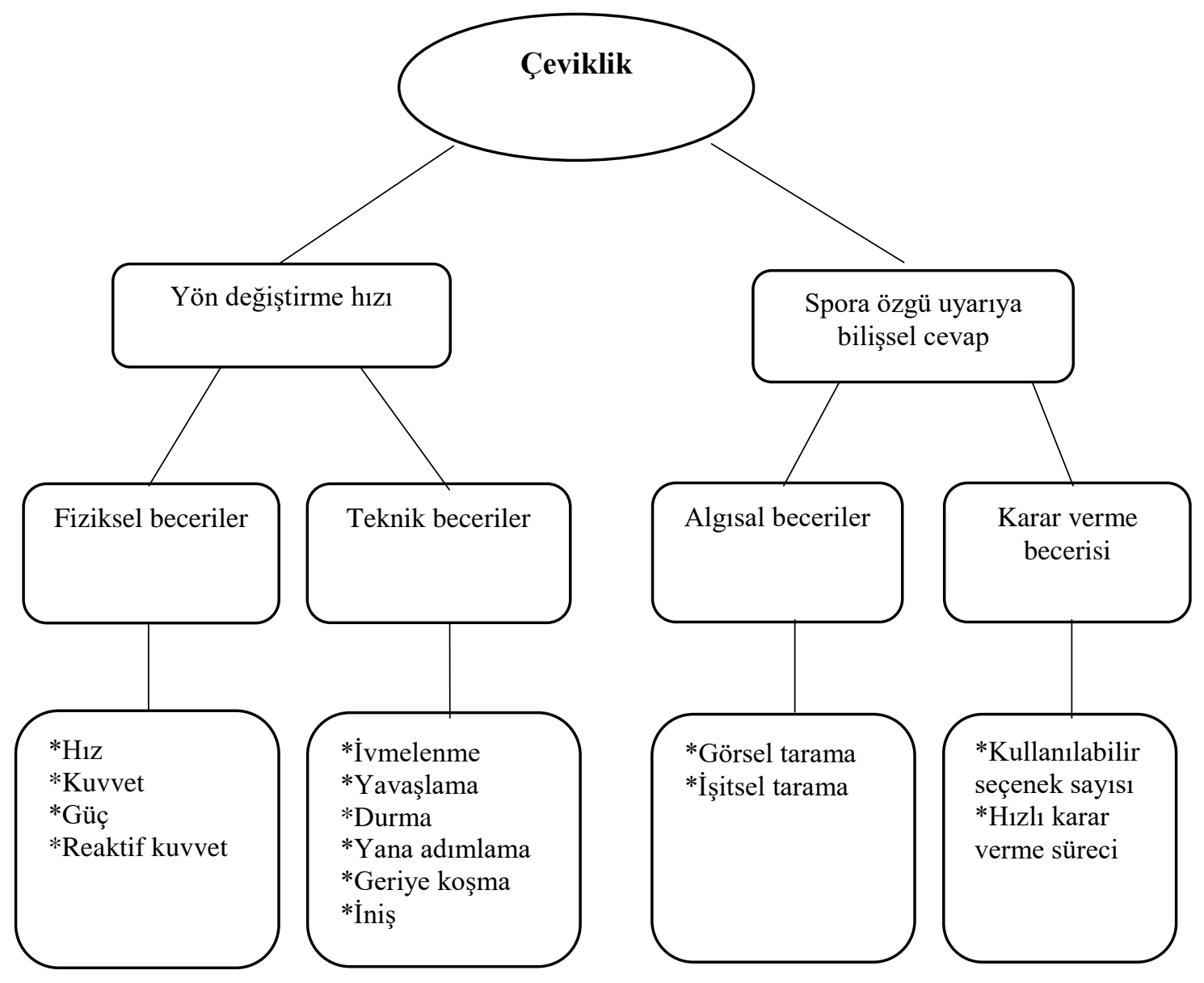

Şema 2. Çevikliğin Şematik Sınıflandırılması (Turner, 2011).

Yukarıdaki şemalarda vurgulandığı gibi çeviklik performansı için sporcuların yön değiştirme yeteneği, sprint hızı, gücü, reaksiyon zamanı gibi özellikleri avantaj sağlamaktadır. Bunun yanında birçok spor branşında çevre kontrolü sağlama, ortamda olup bitenlerin farkında olma ve rakip veya top gibi oyun içi değişkenlerin hareketlerini sezme gibi faktörlerde çeviklik performansına etki ettiği belirtilmektedir (Young \& Farrow, 2006). Dolayısıyla çeviklik becerisi birçok farklı özellikten etkilenmekte ve çok sayıda beceriyle iç içedir.

\section{Çevikliğin Geliştirilmesi}

Antrenörler ve sporcular başarı sağlayacak etkili ve pratik alternatifleri sürekli olarak araştırmaktadırlar (Asadi, 2013; Asadi, Arazi ve ark., 2017; Loturco ve ark., 2017). Çeviklik performansının birçok spor dalında çok önemli bir belirleyici olduğu konusunda fikir birliği oluşmuştur fakat nasıl geliştirileceği konusunda yeterli bilgi mevcut değildir. Çeviklik performansı genelde kuvvet, hız, yön değiştirme, çabukluk ve denge gibi performans faktörleri çevikliğe aktarılarak geliştirilmeye çalışılmıştır (Loturco ve ark., 2017; Sporis ve ark., 2010; Thomas, French, \& Hayes, 2009; Turner, 2011). Fakat yapılan birçok çalışma diğer performansların çevikliği doğrudan etkilemediği ve diğer antrenman yöntemleriyle edinilen becerilerin çevikliğe aktarılmada sınırlı rol oynadığını ortaya koymaktadır 
(Morrison, Albert, \& Kuruganti, 2016; Paul ve ark., 2016; Sporis, Milanovic, Trajkovic, \& Joksimovic, 2011; Young \& Farrow, 2006). Örneğin sprint ve yön değiştirme kısmi olarak çeviklik performansına avantaj sağlayabilir ancak, özgünlük ilkesinden dolayı çevikliğe tamamıla etki etmesinin beklenemeyeceği belirtilmektedir (Sporis ve ark., 2010). Bazı araştırmacılar çeviklik ve sprint performansını ölçmede kullanılan testler üzerinde faktör analizi yapmışlar ve sprint ve çeviklik özelliklerinin farklı faktörler tarafından temsil edildiğini bulmuşlardır (Mayhew, Piper, Schwegler \& Ball, 1989). Bu da hız ve çeviklik becerilerinin kısmen ortak bileşenlerden etkilendiği ama bunların yanında farklı bağımsız özelliklerden oluşan iki farklı nitelik olduğunu ortaya koymaktadır (Sporis ve ark., 2010). Bunun yanında yapılan çalışmalarda bazı sportif becerilerin, çeviklik performansına nispeten aktarılabildiği, ya da çeviklik performansını geliştirmek için planlanan antrenmanlara daha hazır bir alt yap1 sağlayabileceği düşünülmektedir (Asadi, 2013; French, \& Hayes, 2009; Young \& Farrow, 2006). Örneğin koşu tekniği, yön değiştirme, sıçrama ve yere inme gibi temel hareket yapıları daha iyi olan sporcular antrenman sürecinden daha fazla fayda sağlayacakları ve rekabette daha başarılı olacakları vurgulanmaktadır (Sporis ve ark., 2010).

Çeviklik ile ilgili yapılan antrenman programları ve literatürdeki uygulamaların çoğu önceden planlanmış yön değiştirmeler içerir. Yani önceden hazırlanmış bir alanda çizgiler, koniler gibi belli noktalarda, belli yönlere hareket kalıpları içeren protokoller uygulanmaktadır (Loturco ve ark., 2017; Sekulic ve ark., 2013; Stewart ve ark., 2014; Thomas, French, \& Hayes, 2009). Ancak bu tür planlanmış protokollerde iyi sonuçlar elde eden sporcuların çok çevik olduğu söylenemez. Çünkü atletik yetenekleri üst düzeyde olan bir sporcunun algılama ve karar verme yetenekleri düşük olsa bile, diğerlerine göre daha çevik olduğu gibi yanıltıcı bir sonuca ulaş1labileceği belirtilmektedir (Young \& Farrow, 2006).

Çeviklik antrenmanlarında mutlaka bir uyarana ve buna bağlı bilişsel süreçlere yer verilmelidir. Çevikliğin geliştirilmesinde video temelli yöntemler, maliyet ve zaman gereksinimi yüzünden uygulanması zor olsa da bilişsel faktörleri geliştirmek için oldukça faydalı olabileceği savunulmaktadır (Paul ve ark., 2016). Bunun yanında antrenörler, çeviklik antrenmanlarında insan faktörünü göz ardı etmemelidir. Çünkü uyarıcı olarak sadece spor aleti kullanmanın, dolayısıyla rakibin kinematik ipuçlarını ihmal etmenin, bu becerinin oyun içi mekaniğine taşınmasına engel olabileceği vurgulanmaktadır (Turner, 2011). Çevre kontrolü iyi olan, sezgisi kuvvetli, ortam bilgilerini algılamada ve karar vermede iyi bir beceriye sahip sporcuların, rakiplerinin duruşundan ve hareketlerinden sezinleme yapabilecekleri belirtilmektedir (Simonek, Horička \& Hianik, 2016; Zemkova, 2016; Zouhal ve ark., 2018). Örneğin, bu sporcular rakiplerinin hızını, duruşunu ve uzuvlarının açısını bilgi kaynağı olarak kullanıp olasılıkları değerlendirebilecekleri ve rakibine üstünlük sağlamak için bu ipuçlarını kullanabileceği vurgulanmaktadır (Paul ve ark., 2016; Young \& Farrow, 2006).

Çeviklik becerisinin sadece alt gövdedeki kas grubundan ziyade, bütün vücudun katıldığı bir kinetik zincir fonksiyonu olarak düşünmenin daha doğru olacağı belirtilmektedir (Young \& Farrow, 2006). Yani çevikliği geliştirmek için yapılan hareketlerde tüm vücudun katılımı sağlanmalı, algılama ve karar verme gibi bilişsel faktörler dahil edilmelidir. 
Literatürde çeviklik performansını değerlendirmeye yönelik birçok farklı test bataryasının uygulandığı çok sayıda araştırma varken, bu performansın nasıl artırılacağına yönelik çalışma sayısının sınırlı olduğu belirtilmiştir (Young \& Farrow, 2006). Çeviklik performansının geliştirilmesine yönelik en kapsamlı çalışmalardan birisi Turner (2011) tarafından yapılmış ve Tablo 3 de sunulmuştur.

Tablo 3. Çevikliğin Geliştirilmesi (Turner, 2011)

\begin{tabular}{|c|c|c|}
\hline Aşamalar & Tanım & Örnek Driller \\
\hline Teknik driller & $\begin{array}{l}\text { Kapalı bir alanda belirli } \\
\text { hareketlere yoğunlaşmak ve } \\
\text { geliştirmek için kullanılır. }\end{array}$ & $\begin{array}{l}\text { *İvmelenme } \\
\text { *Yavaşlama } \\
\text { *Sol ve sağ ayakla sonlandırma } \\
\text { *180 dönüşler } \\
\text { *Yana adımlama }\end{array}$ \\
\hline Hareket Kalıpları & $\begin{array}{l}\text { Spora özgü iki veya daha fazla } \\
\text { hareket dizisi içerir. } \\
\text { Bu birleşik bir beceri şeklinde } \\
\text { öğretilir. }\end{array}$ & $\begin{array}{l}\text { *Tenis: } 3 \mathrm{~m} \text { ivmelenme, yavaşlama, } 2 \mathrm{~m} \text { sola } \\
\text { adımlama, } 180^{\circ} \text { dönüş, } 5 \mathrm{~m} \text { ivmelenme } \\
\text { *Futbol: } 2 \mathrm{~m} \text { sağa adımlama, } 10 \mathrm{~m} \text { ivmelenme, sağ } \\
\text { ayakla durma, } 3 \mathrm{~m} \text { ivmelenme, yavaşlama }\end{array}$ \\
\hline $\begin{array}{l}\text { Reaktif çeviklik } \\
\text { antrenmanları } \\
\text { (Reactive Agility } \\
\text { Training - RAT) }\end{array}$ & $\begin{array}{l}\text { Spora özgü bir uyarana ani ve } \\
\text { rastgele tepki vermeyi gerektiren } \\
\text { oyun benzeri durumları } \\
\text { güçlendirmek için tasarlanır. }\end{array}$ & $\begin{array}{l}\text { *Copy cat (bir kişi hareketleri yapar, diğeri en hızlı } \\
\text { şekilde onu taklit eder) } \\
\text { *Mirror image (hareketi yapanın aynadaki yansıması } \\
\text { olarak karşılık verilmeye çalış1lır) } \\
\text { *Shadows (bir kişi bir hedefe ulaşmaya, diğeri } \\
\text { engellemeye çalışır) }\end{array}$ \\
\hline $\begin{array}{l}\text { Zamansal } \\
\text { duraksama } \\
\text { antrenmanı }\end{array}$ & $\begin{array}{l}\text { Sporcuların ipuçları ile sonuç } \\
\text { arasındaki ilişsiyi kavramalarını } \\
\text { sağlar }\end{array}$ & $\begin{array}{l}\text { Sporcu video görüntüleri kullanılarak rakibinden } \\
\text { kurtulmaya çalışabilir. Video, rakip yön değiştirmeye } \\
\text { başlamadan hemen önce durdurulur. Sporcu mevcut } \\
\text { ipuçlarını kullanarak ona göre tepki vermelidir. }\end{array}$ \\
\hline
\end{tabular}

Turner (2011) yaptığı çalışmasında çevikliğin sınıflandırılması ve geliştirilmesi hususunda detaylı bilgiler sunmuştur. Ayrıca çalışmasında hem fiziksel hem de bilişsel performansı geliştirmeye yönelik katkı sağlamıştır.

\section{Çeviklik İle İlişkili Kavramlar}

Çeviklik performansının ilişkili olduğu kavramlar içerisinde, kalıtımsal özellikler, dinamik denge, reaksiyon zamanı, eklem hareketliliği, çabuk kuvvet, hız, yaratıcı düşünebilme, konsantrasyon, yön değiştirme hızı, esneklik ve koordinasyon gibi bir çok faktörden bahsetmenin mümkün olduğu belirtilmektedir (Chaouachi ve ark., 2014; Karacabey, 2013; Sporis ve ark., 2010). Literatürde bazı kavramların çeviklikle ilişkisinin incelendiği çalışmalarda çeşitli sonuçlara ulaşılmıştır. Örneğin kuvvet, güç, hız, denge, esneklik ve reaktif kuvvet gibi birçok sporda gerekli olan temel becerilerin çeviklik ile yüksek düzeyde ilişkili olduğu çalışmalara sıklıkla rastlanırken (Jovanovic, Sporis, Omrcen, \& Fiorentini, 2011; Mann ve ark., 2016; Spiteri ve ark., 2014; Spiteri ve ark., 2015), aralarında yeterli düzeyde ilişkinin olmadığı ve bu becerilerin farklı faktörler tarafından temsil edildiği yönünde sonuçlara ulaşıldığı da gösterilmektedir (Erdem ve ark., 2 015; Mayhew, Piper, Schwegler \& Ball, 1989; Sporis ve ark., 2011).

Sprint ve çeviklik arasındaki ilişkiyi inceleyen çalışmalarda farklı sonuçlara ulaşıldığı görülmüştür. Bazı çalışmalarda çeviklik ve sprint arasında anlamlı bir ilişki bulunmazken 
(Sassi ve ark., 2009; Scanlan, Humphries, Tucker, \& Dalbo, 2014; Sporis ve ark., 2011), baz1 çalışmalarda ise kısa mesafe sprint ve ivmelenme performansının çeviklik ile oldukça ilişkili olduğu, bu özelliklerin performans değişimi konusunda aynı yönde güvenilir bilgi sağladığı vurgulanmaktadır (Jones, Bampouras, \& Marrin, 2009; Mann ve ark., 2016). Bunun yanında bazı araştırmacılar çeviklik ve çabukluk antrenmanlarının sprint performansına olumlu yönde katkı sağladığını belirtmektedir (Jovanovic, Sporis, Omrcen, \& Fiorentini, 2011).

Kuvvet ve çeviklik ilişkisi özellikle alt gövde kuvveti olarak incelenmektedir. Yapılan çalışmalar, özellikle yön değiştirme içeren ve bilişsel özelliklerin dahil edilmediği testlerde çeviklik performansının, dinamik, konsantrik, eksantrik ve izometrik kasılma kuvvetiyle oldukça ilişkili olduğunu ortaya koymaktadır (Jones, Bampouras, \& Marrin, 2009; Spiteri ve ark., 2014).

Reaktif kuvvet, çeviklik ile ilişkili olan performans ölçütlerinden birisidir. $\mathrm{Bu}$ özellik gerilme-kısalma döngüsünde, eksantrik fazdan konsantrik faza hızlı bir geçiş yapabilme kabiliyeti olarak tanımlanabilir ve çevikliği etkileyen faktörlerden birisi olarak kabul edilmektedir (Young, Wilson, \& Byrne, 1999). Dolayısıyla özellikle sıçrama becerisi ile çeviklik arasındaki ilişki çok sayıda araştırmacı tarafından incelenmiştir. Bu araştırmaların çoğunda sıçrama ve çeviklik becerilerinin oldukça ilişkili olduğu belirtilmektedir (Hazır, Mahir ve Açıkada, 2010; Sassi ve ark., 2009). Ayrıca çeviklik antrenmanlarının sıçrama performansına, ya da sıçrama antrenmanlarının çeviklik performansına olumlu yönde etkisinin olduğunu savunan birçok çalışma bulunmaktadır (Asadi, 2013; Jovanovic, Sporis, Omrcen, \& Fiorentini, 2011; Khodaei, Mohammadi \& Badri, 2017; Sporis ve ark., 2010; Thomas, French, \& Hayes, 2009).

Denge, çeviklik için gerekli birçok beceriden bir tanesi olarak kabul edilir. Ancak çeviklik ve denge arasındaki ilişkinin incelendiği çalışmalarda farklı sonuçlara ulaşılmıştır. Örneğin bazı çalışmalarda denge ile çeviklik arasında anlamlı bir ilişki tespit edilirken (Okudur ve Sanioğlu, 2012; ), bazı çalışmalarda herhangi bir ilişki bulunamamıştır (Erdem ve ark., 2015).

Antropometrik değerler ve vücut kompozisyonunun çeviklik ile ilişkisini incelediğimizde, sonuçların kısmen farklılaştığı görülmektedir. Örneğin bazı çalışmalarda vücut kitle indeksi (VKI) ve çevikliğin oldukça yüksek düzeyde bir ilişkisinin olduğu bulunurken (Erdem ve ark., 2015; Morrison, Albert, \& Kuruganti, 2016; Spiteri ve ark., 2015), bazı çalışmalarda da bu ilişkinin yeterince anlamlı olmadığı bulunmuştur (Scanlan, Humphries, Tucker ve Dalbo, 2014).

Çeviklik ile ilişkili olduğu düşünülen kavramlardan bir diğeri de 1sınmadır. Bu çalışmalarda genel olarak dinamik ısınmanın, statik ısınma ve aerobik koşu ile ısınmaya göre daha fazla katkı sağladığı bulunmuştur (Amiri-Khorasani, Sahebozamani, Tabrizi ve Yusof, 2010; McMillian, Moore, Hatler ve Taylor, 2006; Van Gelder ve Bartz, 2011). Bunun yanında sadece aerobik koşu ile yapılan ısınmanın da statik ısınmaya göre çeviklik performansına daha fazla katkı sağladığı vurgulanmaktadır (Amiri-Khorasani, Sahebozamani, Tabrizi ve Yusof, 2010). 
Deneyim ve spor yaşı gibi faktörler de çeviklik ile ilişkisi araştırılan kavramlar olmuştur. Örneğin bir çalışmada daha deneyimli futbolcuların diğerlerine göre hem dinamik hem de statik ısınma sonrası Illinois testinden aldıkları skorların daha yüksek olduğu ortaya konmuştur (Amiri-Khorasani, Sahebozamani, Tabrizi ve Yusof, 2010). Benzer şekilde başka bir çalışmada profesyonel futbolcuların, amatör futbolculara göre daha iyi çeviklik performansı sergilediği bulunmuştur (Kaplan, Erkmen ve Taskin, 2009). Yani yıllarca becerileri geliştiren antrenmanların çevikliği de geliştirdiğini söylemek mümkündür.

Teknik, çeviklik performansını belirleyen önemli unsurlardan biri olarak kabul edilir ancak araştırmalarda fiziksel faktörlere daha fazla odaklanıldığı görülmektedir (Paul ve ark., 2016). Çünkü teknik kavramının tam olarak nasıl ölçüleceği konusunda bir kesinlik yoktur. Bir sporcu grubunda yön değiştirme performansını etkileyen faktörleri belirlemek amaciyla yapılan bir çalışmada 3D biyomekanik kamera sistemi ile video kaydı yapılmıştır. Araştırmanın sonuçlarına göre çeviklik performansı daha yüksek sporcuların; temas zamanı, geçiş, reaksiyon kuvveti, gövde yükseklik merkezi, pelvis rotasyonu, omurga rotasyonu, kalça adduksiyon ve abduksiyon değişkenlerinde anlamlı ilişkiler bulunmuştur (Morrison, Albert, \& Kuruganti, 2016). Yani çeviklik becerisinin birçok farklı teknik stratejiden etkilendiği söylenebilir. Ayrıca yapılan çalışmalarda çeviklik performansı daha yüksek olan bireylerin, daha kısa temas süresine sahip oldukları ve daha fazla kuvvet uyguladıkları tespit edilmiştir (Jones, Bampouras, \& Marrin, 2009; Spiteri ve ark., 2015).

Ortam kontrolü, sezinleme, bir uyaranı algılama ve yanıt verme gibi bilişsel faktörlerin, günümüzde bu performansı oluşturan temel unsurlar olduğu kabul edilmektedir. Reaktif çeviklik testini değerlendirmek amacıyla yapılan bir çalışmada, testin tamamlanma süresi ve çeşitli bileşenler arasındaki ilişki incelenmiştir. Bu çalışmada testi yöneten bir kişi, sporcunun yön değiştirmesini sağlamak için yana adımlar atarak sporcu için bir uyaran oluşturmuştur. Test video analizi ve elektronik zamanlama tekniği kullanılarak analiz edilmiştir. İlişkileri incelemek amacıyla testi yöneten kişinin uyarı süresi, deneğin uyarıcıya yanıt verme süresi, yön değiştirme ve sprint ile verdiği tepki süresi belirlenmiştir. Araştırmanın sonuçlarına göre, testin toplam zamanı ile uyarıcıya yanıt verme süresi arasında 0,77 ; tepki süresi ile 0,59 ; uyarı süresi ile de 0,37 düzeyinde anlamlı ilişki tespit edilmiştir (Young ve Willey, 2010). Başka bir çalışmada reaktif çeviklik testi ve (10 metre) $10 \mathrm{~m}$ sprint testi arasındaki ilişki önceden planlandığında hem să̆ hem de sol yönler açısından, planlı olmadan yapılan durumdan daha yüksektir (Lockie ve ark., 2014). Yani bilişsel faktörler olmadan sprint ve çeviklik arasındaki ilişki oldukça yüksek iken, bir uyaranı algılama ve yanıt verme gibi bilişsel faktörler eklendiğinde aynı sonucun tekrar edilmeme durumunun söz konusu olduğu belirtilmektedir (Lockie ve ark., 2014; Scanlan, Humphries, Tucker ve Dalbo, 2014).

\section{Çeviklik Testleri}

Çeviklik alt bileşenleri açısından en karmaşık yapıya sahip sportif becerilerden birisidir. Dolayısıyla da bu karmaşık beceriyi ölçmek için çok sayıda test geliştirilmiştir (Sheppard ve Young, 2006; Simonek, Horicka ve Hianik, 2016; Young ve Farrow, 2006). Ancak çevikliği ölçmek için kullanılan en yaygın testler bile günümüzde yeterli görülmemektedir. Bu testler özellikle önceden planlanmış bir hareket dizisini içerdiği ve bilişsel faktörlere yer vermediği 
için eleştirilmektedir. Özellikle sadece hız koşusu ve yön değiştirme becerisi içeren testlerin çeviklik testi olarak kullanılması bazı araştırmacılar tarafından uygun bulunmamaktadır. $\mathrm{Bu}$ gelişmelerin çevikliğin değerlendirilmesinde ve yorumlanmasında bazı karışıklıklara sebep olduğu belirtilmektedir (Sheppard ve Young, 2006; Sekulic ve ark., 2013; Stewart ve ark., 2014; Zemkova, 2016).

Günümüzde yaygın olarak kullanılan çeviklik testlerinden, Pro-çeviklik, T-test, Illinois testi ve 505 çeviklik testleri birleşik becerileri ölçmekte ve mümkün olan en hızlı zamanda önceden planlanmış bir hareket dizisini tamamlamayı içermektedir. Çeviklik becerisi ile ilgili yapılan son uyarlamalar ile birlikte bu testlerin, çeviklik testi değil yön değiştirme testi olarak kabul edilmesi uygun görülmektedir. Bu testler düz sprint, geriye koşma, farklı açılarda yön değiştirmeler, yanal kayma adımları ve çapraz adımlama gibi çeşitli hareket kalıpları içermektedir (Young ve Farrow, 2006; Turner, 2011).

Çeviklik testleri arasında yön değiştirme sayısı, yön değiştirme açısı, sprint mesafesi ya da önceden planlı olup olmaması gibi birçok farklılık olduğu görülmektedir (Hart ve ark., 2014; Kirby, 1971; Sporis ve ark., 2010; Stewart, Turner ve Miller, 2014; Young ve Farrow, 2006; Mann ve ark., 2016). Ayrıca çeviklik testleri arasında kullanılan enerji sistemleri açısından da farklılıkların olduğu belirtilmektedir (Young ve Farrow, 2006). Örneğin (20 metre) 20m sprint ve (100 metre) 100m sprint testlerinde gerekli sürenin ve kullanılan enerji sistemlerinin birbirinden farklı olduğunu düşünürsek, çeviklik testlerinin toplam mesafesi ve süresi gibi değişkenlerin de kullanılan enerji sistemlerini oransal olarak farklılaştıracağı görülmektedir (Hart ve ark., 2014; Kirby, 1971; Sporis ve ark., 2010; Stewart ve ark., 2014).

Çeviklik testlerinin bazılarında önceden planlanmış protokoller uygulanırken bazılarında da 1şık, ses, görüntü ya da insan gibi farklı uyaranlara tepki vermeyi gerektiren protokoller uygulanmaktadır (Paul ve ark., 2016; Turner, 2011). Bu testlerde çeviklik performansı, bir uyaranın başlangıcından o uyaranı algılama ve reaksiyon gösterme gibi bir sürecin parçaları olarak yer almaktadır. Bu yüzden bir uyarana karşı gösterdiği reaksiyon süresi kısa olan atletler çeviklik performansı için bir avantaj sağlamaktadır (Young ve Farrow, 2006). Ancak birçok sporda gerçeğe uygunluk açısından en güvenilir uyaranın insan olması sebebiyle testlerde uyaran olarak insan kullanılmasının ve rakibin kinematik ipuçlarının değerlendirilmesinin daha geçerli bilgiler sunacağı belirtilmektedir (Paul ve ark., 2016; Turner, 2011).

Çeviklik testleri ile ilgili çalışmaları incelediğimizde farklı sonuçlara ulaşıldı̆̆ı görülmektedir. Bazı araştırmacılar yaygın olarak kullanılan çeviklik testlerinin sonuçlarının birbirleri ile oldukça tutarlı olduğunu bulurken (Sekulic ve ark., 2013; Stewart ve ark., 2014), diğerleri de bu testlerin sonuçlarının birbirlerinden farklı olduğunu bulmuştur (Raya ve ark., 2013; Hazır, Mahir ve Açıkada, 2010). Örneğin bir çalışmada Edrgen side-step test, T-test ve Illinois testi arasında geçerlik ve güvenirlik açısından anlamlı bir farkın olmadığı belirtilmiştir. Ayrıca Illinois testi ile T-test arasında 0,76 düzeyinde pozitif bir ilişki bulunmuştur (Raya ve ark., 2013). Başka bir çalışmada T-test, zig-zag testi, 20-yard mekik testi, $180^{\circ}$ dönüşlü çeviklik testi ve ileri-geri koşu çeviklik testi uygulanmıştır. Araştırmanın sonuçlarına göre 5 farklı çeviklik testinin birbirleriyle anlamlı pozitif bir ilişkisi $(\mathrm{r}=0,75$ 0,91 arasında) vardır (Sekulic ve ark., 2013). Başka bir araştırmada ise Illinois, L-koşu, Pro- 
çeviklik, T-test ve 505 testlerinin tamamının yüksek düzeyde güvenilir olduğu bulunmuştur (0,88-0,95 arasında). Ayrıca, bütün testlerin birbirleriyle pozitif ve yüksek düzeyde ilişkili olduğu sonucuna ulaşılmıştır (0.84-0,89 arasında) (Stewart ve ark., 2014). Yani çevikliği ölçmek için kullanılan testlerin genelde birbiriyle paralel sonuçlar verdikleri görülmektedir. Ancak bu testlerin birçoğunda bilişsel faktörlere yer verilmemiş ve sadece mekanik beceriler ölçülmüştür. Bunun yanında yapılan başka bir çalışmada T-testi ve 505 çeviklik testi arasındaki 0,81 yüksek ilişki olarak bulunurken, Reaktif çeviklik testi ile T-testi arasında 0,28 ve Reaktif çeviklik testi ile 505 Çeviklik testi arasında da 0,27 düzeyinde düşük ilişki bulunmuştur (Spiteri ve ark., 2014). Başka bir deyişle bilişsel faktörlerin çeviklik testlerine dahil edilmesi ile birlikte, çevikliği ölçmek için yaygın olarak kullanılan testlerden daha farklı sonuçlara ulaşılabilmektedir. Aşağıda çeviklik becerisinin test edilmesinde sıklıkla kullanılan testlere yer verilmiştir.

Çeviklik T Testi: $\mathrm{T}$ testi, $10 \mathrm{~m}$ uzunluğu ve $10 \mathrm{~m}$ genişliği olan bir alanda $\mathrm{T}$ şeklinde oluşturulmuş 4 temas noktasından oluşmaktadır (Şekil 1). Deneğin bu temas noktaları arasında farklı yönlere, farklı şekillerde hareket etmesini gerektiren bir seriyi en kısa sürede tamamlaması amaçlanır. Bu testin diğer çeviklik testlerinden farkı denek daima aynı yöne bakar. Yön değiştirme işini sağa ve sola kayma adımlarıyla ya da geriye koşarak yapar. Bu test ikişer adet $90^{\circ}$ 'lik ve $180^{\circ}$ 'lik dönüşün yanı sıra, $10 \mathrm{~m}$ ileri, $10 \mathrm{~m}$ sağa, $10 \mathrm{~m}$ sola ve $10 \mathrm{~m}$ geriye olmak üzere toplamda 40m'lik bir mesafenin kat edilmesini gerektirir.

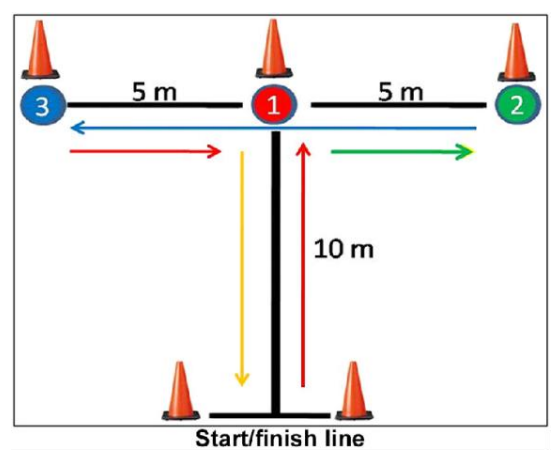

Şekil 1. Çeviklik T testi (Raya ve ark., 2013)

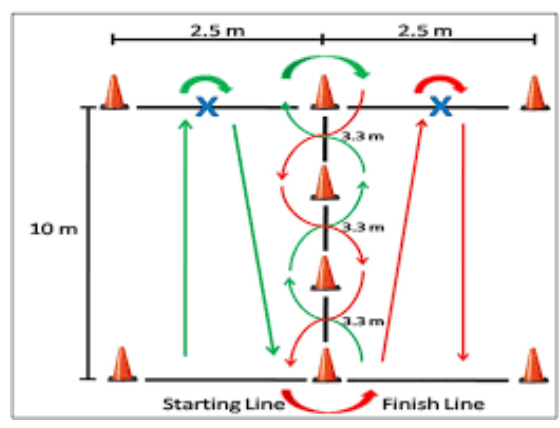

Şekil 2. Illinois Çeviklik Testi (Raya ve ark., 2013)

Illinois Çeviklik Testi: Illinois testi de günümüzde sprint ve yön değiştirme becerisini ölçebilen ancak bilişsel faktörleri göz ardı ettiği için çevikliğin tüm bileşenlerini karşılamadığı düşünülen bir testtir. Bu test $5 \mathrm{~m}$ genişliği ve $10 \mathrm{~m}$ uzunluğu olan bir alanda yapılır. 10m uzunluğun orta hattı eşit aralıklarla (yaklaşık $3.3 \mathrm{~m}$ ) yerleştirilen konilerle 3'e bölünmüş̧ür (Şekil 2). Bu test yaklaşık 40m düz koşu ve $20 \mathrm{~m}$ koniler arasında slalom koşu içermektedir. Bu test 5 adet yaklaşık $180^{\circ}$ 'lik tam dönüşün yanı sıra, koniler arasında tam olmayan 6 adet dönüş daha içerir. Illinois testi, yaygın olarak kullanılan çeviklik testleri arasında kat edilecek mesafe ve geçirilen süre açısından en uzun testtir. Bu testin başlangıç aşamasında denekler yüzüstü yatar pozisyonda ve eller omuz hizasında yere temas edecek şekilde hazır beklerler (Hazır ve ark., 2010). 


\section{Pro-Çeviklik Testi:}

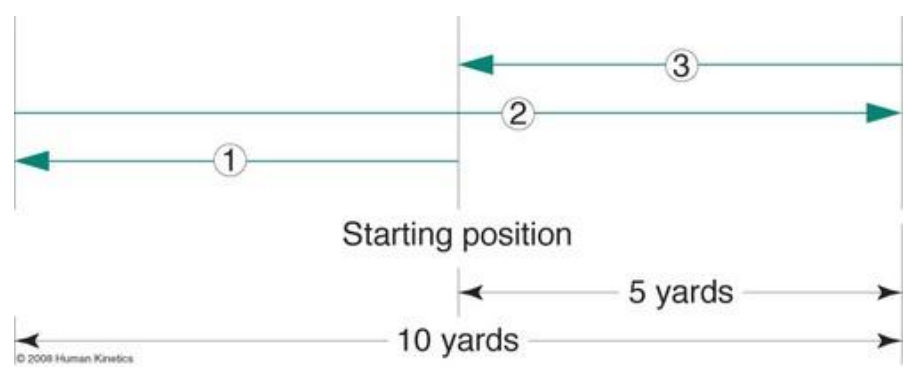

Şekil 3. Pro-Çeviklik (Pro-Agility) Testi

$\mathrm{Bu}$ test için 10 yard $(9.14 \mathrm{~m})$ uzunluğundaki bir alan üzerinde toplam 20 yard'lık bir mesafenin kat edilmesinden ibarettir. 2 adet $180^{\circ}$ 'lik dönüş ve düz sprint koşularını içerir (Şekil 3). Bu testin de günümüzde ivmelenme, durma, yön değiştirme ve sprint gibi çeviklik bileşenleri hakkında bilgi vermesine rağmen, önceden planlı olması ve bilişsel faktörlere yer vermediği için geçerliği konusunda eleştiriler vardır.

505 Çeviklik Testi: Bu test $15 \mathrm{~m}$ uzunluğundaki bir parkurun son 5m'lik kısmının gidiş ve dönüşü arasındaki sürenin ölçülmesinden ibarettir (Şekil 4). Kısa süreli ve oldukça basit uygulanabilir olmasına rağmen hareket kalıbı önceden belli olduğu için çevikliğin bilişsel unsurları hakkında bilgi vermez. Daha çok ivmelenme, durma ve yön değiştirme gibi beceriler hakkında bilgi verir. Testin başlangıç noktasından itibaren ilk 10m içindeki süre test skoruna dahil edilmez. Daha sonraki 5m'lik mesafe ilk olarak geçildiğinde zaman cinsinden kaydedilmeye başlanır, aynı mesafenin dönüşünde ise kayıt sonlandırılır.

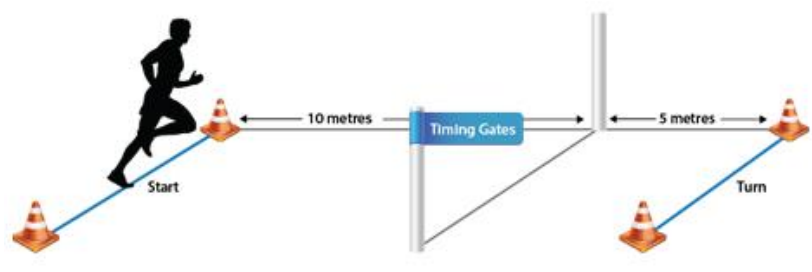

Şekil 4. 505 Çeviklik Testi

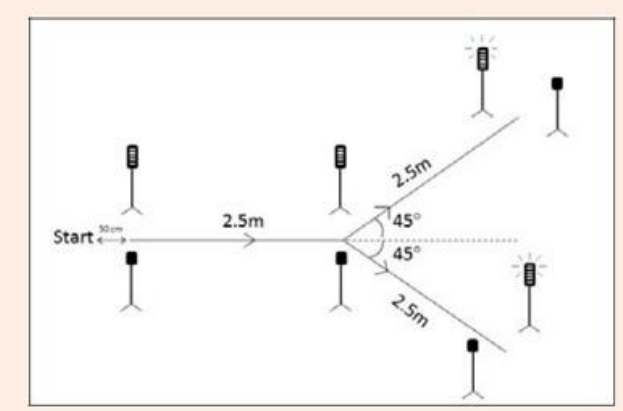

Şekil 5. Reaktif Çeviklik Testi

Reaktif Çeviklik Testi: Reaktif çeviklik testi $45^{\circ}$ lik tek yön değiştirme ve toplamda 5m koşma becerisinden ibarettir. Bu testin, yaygın olarak kullanılan diğer çeviklik testlerinden fark1 yön değiştirme işleminden hemen önce bir uyaran (insan, ses, video veya 1şık) kullanılır ve denek değiştireceği yönü kendisi tercih eder. Dolayısıyla diğer testlere göre algılama ve karar verme gibi bilişsel faktörler hakkında nispeten daha fazla bilgi verir. Ancak bu testin de çevikliği ölçme de tam olarak yeterli olduğu söylenemez. Çünkü yön değiştirme için sadece iki seçenek vardır ve tahmin edilebilme ihtimali yüksektir. Ayrıca mesafe ve yön değiştirme sayısı da oldukça azdır. 


\section{SONUÇ VE ÖNERILLER}

Çeviklik, sportif performansı belirleyen önemli bir faktördür. Ancak bu kavram, geniş kapsamlı ve karmaşık bir yapıya sahip olması sebebiyle zaman içerisinde farklı yorumlanmış ve uygulamada bazı tutarsızlıklara neden olmuştur. Çeviklik, günümüzdeki bakış açısıyla hem fiziksel hem de bilişsel birçok faktörden etkilenen sportif bir beceridir. Uzun yıllardır çeviklik performansını ölçtüğü kabul edilen birçok testin sprint, ivmelenme, yavaşlama ve yön değiştirme gibi becerileri ölçtüğü; ancak bu sonuçların tüm çeviklik bileşenleri hakkında bilgi veremeyeceği kabul edilmektedir. Bunun yanında çevikliği ölçmede kullanılan testler, yön değiştirme sayısı ve açısı, sprint mesafesi, bir uyarana tepki içermesi, önceden planlı olup olmaması, algılama ve karar verme becerilerini içerip içermediği, hatta kullanılan enerji sistemi gibi pek çok konuda farklılık içermektedir.

Çeviklik performansına yeni yaklaşımlar, bu kavramın mutlaka sezgi, çevre kontrolü, görsel tarama, hareket kalıplarını tanıma gibi algılama ve karar verme temelinde birçok bilişsel faktörü içerdiği yönündedir. Dolayısıyla bu faktörleri içeren yeni testler ve bu performansı geliştirmeye yönelik yeni antrenman yöntemlerinin tasarlanması gerektiği düşünülmektedir. Çeviklik performansının içeriğinde bir uyaranın algılanıp tepki verme niteliğinde becerilerin olması gerektiği ve rakibe karşı mücadele verilen sporlarda bu uyaranın büyük ölçüde insan olması gerektiği söylenebilir. Ayrıca yapılacak olan yeni çalışmalarda çevikliğin alt bileşenlerinin, çeviklik performansını ne derecede etkilediği araştırılmalıdır.

\section{KAYNAKLAR}

Amiri-Khorasani, M., Sahebozamani, M., Tabrizi, K. G., \& Yusof, A. B. (2010). Acute effect of different stretching methods on Illinois agility test in soccer players. The Journal of Strength \& Conditioning Research, 24(10), 2698-2704.

Armstrong, R., \& Greig, M. (2018). The Functional Movement Screen and modified Star Excursion Balance Test as predictors of T-test agility performance in university rugby union and netball players. Physical Therapy in Sport, 31, 15-21.

Asadi, A. (2013). Effects of in-season short-term plyometric training on jumping and agility performance of basketball players. Sport Sciences for Health, 9(3), 133-137.

Asadi, A., Arazi, H., Ramirez-Campillo, R., Moran, J., \& Izquierdo, M. (2017). Influence of maturation stage on agility performance gains after plyometric training: A systematic review and meta-analysis. The Journal of Strength \& Conditioning Research, 31(9), 2609-2617.

Bradshaw, R. J., Young, W. B., Russell, A., \& Burge, P. (2011). Comparison of offensive agility techniques in Australian Rules football. Journal of Science and Medicine in Sport, 14(1), 65-69.

Chaouachi, A., Chtara, M., Hammami, R., Chtara, H., Turki, O., \& Castagna, C. (2014). Multidirectional sprints and small-sided games training effect on agility and change of direction abilities in youth soccer. The Journal of Strength \& Conditioning Research, 28(11), 3121-3127.

Chelladurai, P. (1976). Manifestations of agility. Journal of the Canadian Association of Health, Physical Education and Recreation, 42(3), 36-41.

Drake, D., Kennedy, R., Godfrey, M., MacLeod, S., Davis, A., \& Maguire, M. (2017). A step towards a field based agility test in team sports. A perspective on return to play criteria. Physical Therapy in Sport, $28, \mathrm{e} 20$. 
Erdem, K., Çağlayan, A., Korkmaz, O. Z., Kızılet, T., \& Özbar, N. (2015). Amatör futbolcuların vücut kitle indeksi, denge ve çeviklik özelliklerinin mevkilerine göre değerlendirilmesi. Uluslararası Spor, Egzersiz \& Antrenman Bilimi Dergisi, 1(2). Doi:10.18826/ijsets.74084

Greig, M., \& Naylor, J. (2017). The efficacy of angle-matched isokinetic knee flexor and extensor strength parameters in predicting agility test performance. International journal of sports physical therapy, 12(5), 728.

Hart, N. H., Spiteri, T., Lockie, R. G., Nimphius, S., \& Newton, R. U. (2014). Detecting deficits in change of direction performance using the preplanned multidirectional Australian Football League agility test. The Journal of Strength \& Conditioning Research, 28(12), 3552-3556.

Hazır, T., Mahir, Ö. F., \& Açıkada, C. (2010). Genç futbolcularda çeviklik ile vücut kompozisyonu ve anaerobik güç arasındaki ilişki. Spor Bilimleri Dergisi, 21(4), 146-153.

Jones, P., Bampouras, T., \& Marrin, K. (2009). An investigation into the physical determinants of change of direction speed. Journal of Sports Medicine and Physical Fitness, 49(1), 97.

Jovanovic, M., Sporis, G., Omrcen, D., \& Fiorentini, F. (2011). Effects of speed, agility, quickness training method on power performance in elite soccer players. The Journal of Strength \&Conditioning Research, 25(5), 1285-1292.

Kaplan, T., Erkmen, N., \& Taskin, H. (2009). The evaluation of the running speed and agility performance in professional and amateur soccer players. The Journal of Strength \& Conditioning Research, 23(3), 774-778.

Karacabey, K. (2013). Sport performance and agility tests. Journal of Human Sciences, 10(1), 1693-1704.

Khodaei, K., Mohammadi, A., \& Badri, N. (2017). A comparison of assisted, resisted, and common plyometric training modes to enhance sprint and agility performance. The Journal of sports medicine and physical fitness, 57(10), 1237-1244.

Kirby, R. (1971). A simple test of agility. Coach and athlete, 25(6), 30-31.

Lockie, R. G., Jeffriess, M. D., McGann, T. S., Callaghan, S. J., \& Schultz, A. B. (2014). Planned and reactive agility performance in semiprofessional and amateur basketball players. International Journal of Sports Physiology \& Performance, 9(5), 766-771.

Loturco, I., Kobal, R., Kitamura, K., Cal Abad, C. C., Faust, B., Almeida, L., \& Pereira, L. A. (2017). Mixed training methods: effects of combining resisted sprints or plyometric with optimum power loads on sprint and agility performance in professional soccer players. Frontiers in physiology, 8, 1034.

Mann, J. B., Ivey, P. A., Mayhew, J. L., Schumacher, R. M., \& Brechue, W. F. (2016). Relationship Between Agility Tests and Short Sprints: Reliability and Smallest Worthwhile Difference in National Collegiate Athletic Association Division-I Football Players. The Journal of Strength \& Conditioning Research, 30(4), 893-900.

Mayhew, J.L., Piper, F.C., Schwegler, T.M., \& Ball, T.E. (1989). Contributions of speed, agility and body composition to anaerobic power measurements in college football players. Journal of Applied Sports Science Research, 3(4), 101-106.

McMillian, D. J., Moore, J. H., Hatler, B. S., \& Taylor, D. C. (2006). Dynamic vs. static-stretching warm up: the effect on power and agility performance. The Journal of Strength \& Conditioning Research, 20(3), 492-499.

Morrison, K., Albert, W. J., \& Kuruganti, U. (2016). Biomechanical Assessment of Change of Direction Performance in Male University Soccer Players. Paper presented at the ISBS-Conference Proceedings Archive. (Poitiers, France, June 29 - July 3, 2015).

Okudur, A., \& Sanioğlu, A. (2012). 12 yaş tenisçilerde denge ile çeviklik ilişkisinin incelenmesi. Selçuk Üniversitesi Beden Ĕgitimi ve Spor Bilimleri Dergisi, 14(2), 165-170.

Paul, D. J., Gabbett, T. J., \& Nassis, G. P. (2016). Agility in team sports: testing, training and factors affecting performance. Sports Medicine, 46(3), 421-442.

Raya, M. A., Gailey, R. S., Gaunaurd, I. A., Jayne, D. M., Campbell, S. M., Gagne, E., . . Tucker, C. (2013). Comparison of three agility tests with male servicemembers: Edgren Side Step Test, T-Test, and Illinois Agility Test. J Rehabil Res Dev, 50(7), 951-960. 
Sassi, R. H., Dardouri, W., Yahmed, M. H., Gmada, N., Mahfoudhi, M. E., \& Gharbi, Z. (2009). Relative and absolute reliability of a modified agility $\mathrm{T}$-test and its relationship with vertical jump and straight sprint. The Journal of Strength \& Conditioning Research, 23(6), 1644-1651.

Scanlan, A., Humphries, B., Tucker, P. S., \& Dalbo, V. (2014). The influence of physical and cognitive factors on reactive agility performance in men basketball players. Journal of Sports Sciences, 32(4), 367-374.

Sekulic, D., Spasic, M., Mirkov, D., Cavar, M., \& Sattler, T. (2013). Gender-specific influences of balance, speed, and power on agility performance. The Journal of Strength \& Conditioning Research, 27(3), 802-811.

Sheppard, J. M., \& Young, W. B. (2006). Agility literature review: Classifications, training and testing. Journal of Sports Sciences, 24(9), 919-932.

Šimonek, J., Horička, P., \& Hianik, J. (2016). Differences in pre-planned agility and reactive agility performance in sport games. Acta Gymnica, 46(2), 68-73.

Spiteri, T., Newton, R. U., Binetti, M., Hart, N. H., Sheppard, J. M., \& Nimphius, S. (2015). Mechanical determinants of faster change of direction and agility performance in female basketball athletes. The Journal of Strength \& Conditioning Research, 29(8), 2205-2214.

Spiteri, T., Nimphius, S., Hart, N. H., Specos, C., Sheppard, J. M., \& Newton, R. U. (2014). Contribution of strength characteristics to change of direction and agility performance in female basketball athletes. The Journal of Strength \& Conditioning Research, 28(9), 2415-2423.

Sporis, G., Milanovic, L., Jukic, I., Omrcen, D., \& Molinuevo, J. S. (2010). The effect of agility training on athletic power performance. Kinesiology: international journal of fundamental and applied kinesiology, 41(1), 65-72.

Sporis, G., Milanovic, Z., Trajkovic, N., \& Joksimovic, A. (2011). Correlation between speed, agility and quickness (SAQ) in elite young soccer players. Acta kinesiologica, 5(2), 36-41.

Stewart, P. F., Turner, A. N., \& Miller, S. C. (2014). Reliability, factorial validity, and interrelationships of five commonly used change of direction speed tests. Scandinavian journal of medicine \& science in sports, 24(3), 500-506.

Thomas, K., French, D., \& Hayes, P. R. (2009). The effect of two plyometric training techniques on muscular power and agility in youth soccer players. The Journal of Strength \& Conditioning Research, 23(1), 332-335.

Turner, A. (2011). Defining, developing and measuring agility. Prof Strength Cond, 22, 26-28.

Van Gelder, L. H., \& Bartz, S. D. (2011). The effect of acute stretching on agility performance. The Journal of Strength \& Conditioning Research, 25(11), 3014-3021.

Young, W., \& Farrow, D. (2006). A review of agility: practical applications for strength and conditioning. Strength \& Conditioning Journal, 28(5), 24-29.

Young, W., Wilson, G., \& Byrne, C. (1999). Relationship between strength qualities and performance in standing and run-up vertical jumps. Journal of Sports Medicine and Physical Fitness, 39(4), 285.

Young, W. B., \& Willey, B. (2010). Analysis of a reactive agility field test. Journal of Science and Medicine in Sport, 13(3), 376-378.

Zemková, E. (2016). Differential contribution of reaction time and movement velocity to the agility performance reflects sport-specific demands. Human Movement, 17(2), 94-101.

Zouhal, H., Abderrahman, A. B., Dupont, G., Truptin, P., Le Bris, R., Le Postec, E., ... \& Bideau, B. (2018). Laterality influences agility performance in elite soccer players. Frontiers in physiology, 9(807), 1-8. 